DOI: $10.5216 /$ cab.v12i1.5894

\title{
ESTUDO ECONÔMICO DA PRODUÇÃO DE CORDEIROS CRUZADOS CONFINADOS ABATIDOS EM DIFERENTES PESOS
}

\author{
Tiago do Prado Paim, ${ }^{1}$ Maximiliano Tadeu Memória Cardoso, ${ }^{2}$ Bárbara Oliveira Borges, ${ }^{3}$ \\ Edgard Franco Gomes, ${ }^{4}$ Helder Louvandini ${ }^{5}$ e Concepta McManus ${ }^{6}$ \\ 1. Bolsista de Iniciação Científica do CNPq/UnB, DF. E-mail: pradopaim@hotmail.com \\ 2. Mestrando em Ciências Agrárias na UNB, DF \\ 3. Graduada em Medicina Veterinária na UnB, DF \\ 4. Bolsista do CNPq / IC / UnB, DF \\ 5. Professor Doutor do Centro de Energia Nuclear na Agricultura, USP, SP \\ 6. Professora Doutora do Departamento de Zootecnia, UFRGS, RS.
}

\section{RESUMO}

Com este estudo objetivou-se avaliar a viabilidade econômica da produção de cordeiros cruzados em confinamento, bem como determinar qual o peso de abate mais rentável. Foram utilizados 53 ovinos, machos e fêmeas, oriundos de três grupos genéticos diferentes: Santa Inês (SI), Ile de France x Santa Inês (ISI) e Texel x Santa Inês (TSI). Agruparam-se os animais em diferentes pesos vivos (PV) para o abate (30, 35, 40 e $45 \mathrm{Kg}$ ). Foram analisados os custos variáveis. O custo operacional por $\mathrm{kg}$ de $\mathrm{PV}$ foi de $\mathrm{R} \$$ 4,01; R\$ 3,58 e R \$ 3,38 para SI, ISI e TSI, respectivamente. Os animais abatidos com $45 \mathrm{~kg}$ de $\mathrm{PV}$ apresentaram custo operacional de R\$3,51/kg de PV produzido, que foi significativamente menor que os demais grupos. A receita estimada de $\mathrm{R} \$ 3,50$ por $\mathrm{kg}$ de $\mathrm{PV}$, mostra que, no Distrito Federal (DF), a ovinocultura não é lucrativa. O uso de práticas de manejo para atingir maior índice de partos duplos pode aumentar a margem de lucro bruta da atividade. O pagamento pelo peso de carcaça e por qualidade da carne e a busca por melhores índices de produtividade e melhor conversão alimentar, obtidos por programas de melhoramento genético, são urgentes para a sustentabilidade da atividade.

PALAVRAS-CHAVES: Custo variável, peso de abate, raça, rentabilidade.

\section{ABSTRACT}

\section{ECONOMIC STUDY OF CROSSBRED FEEDLOT LAMBS SLAUGHTERED AT DIFFERENT WEIGHTS}

The purpose of this study was to evaluate the economic viability of producing crossbred lambs in feedlots, and to determine which slaughter weight is more profitable. Fifty-three male and female animals were used, from three different genetic groups: Santa Inês (SI), Ile de France x Santa Inês (ISI) and Texel x Santa Inês (TSI). The animals were slaughtered at different body weights (BW) $(30,35,40$ and $45 \mathrm{Kg})$. Only variable costs were analyzed, as other costs were presumed to be fixed. The BW operational cost per kg was R\$4.01, R\$ 3.58 and $\mathrm{R} \$ 3.38$ for SI, ISI and TSI, respectively. The animals slaughtered with $45 \mathrm{~kg} \mathrm{BW}$ cost R $\$ 3.51$ per kg of BW produced, which was significantly lower than other groups. With estimated revenue of R\$3.50 per $\mathrm{kg}$ of BW, sheep production in the Federal District (DF) is not profitable. The use of management practices to increase the number of twin births may increase the gross profit margin of the activity. Payment for carcass weight and meat quality as well as the improvement of productivity indices and better food conversion obtained by animal breeding programs are urgently needed to guarantee sheep production profitability.

KEYWORDS: Breed, profitability, slaughter weight, variable costs. 


\section{INTRODUÇÃO}

A produção de ovinos na região Centro-Oeste cresceu $138 \%$ nos últimos dez anos (INSTITUTO FNP, 2008), com destaque para o Distrito Federal (DF), onde o crescimento foi de $337 \%$. Mesmo com o aumento da produção nacional de carne ovina, existe um déficit que, segundo as estimativas, tende a persistir, pois a demanda ainda é superior à oferta, dando espaço para as importações (ALMEIDA JÚNIOR et al., 2004).

Fatores como hábito alimentar e poder aquisitivo exercem grande influência sobre o consumo de carne ovina. Além disso, o baixo consumo de carne ovina no Brasil também está relacionado à qualidade do produto colocado à venda, já que comumente encontram-se no mercado carcaças de baixa qualidade provenientes de animais velhos. Isso acaba gerando tabus alimentares entre os consumidores (ALMEIDA JÚNIOR et al., 2004).

RIBEIRO \& MEDEIROS (2006) observaram um crescimento no consumo de carne ovina no Brasil direcionado para nichos de mercado existentes nas grandes cidades, onde o poder aquisitivo da população é maior. No entanto, esses nichos de mercado exigem qualidade, padronização, cortes especiais e continuidade de abastecimento, exigências muito difíceis de atender, devido à falta de organização da cadeia produtiva (SILVA et al., 2006).

No Brasil, definiu-se como prioridade o aumento da capacidade produtiva e, em consequência, o desfrute dos rebanhos ovinos, com o propósito de atender às necessidades do mercado (BARROS et al., 2005). Uma das formas de se aumentar a capacidade produtiva é o uso do cruzamento de raças especializadas em carne (raças exóticas) com ovelhas deslanadas (raças naturalizadas). O cruzamento beneficia o uso da complementaridade entre raças, prática que favorece a conjugação das características desejáveis de cada uma delas e a exploração da heterose. Entretanto, são necessárias mais informações sobre a avaliação de cruzamentos entre diferentes raças de ovinos.

A Santa Inês é a raça ovina de maior expansão no território nacional, visto que é encontrada em todo o Nordeste, Sudeste, Centro-Oeste e Norte do país. É uma raça deslanada que surgiu do cruzamento das raças Morada Nova, Crioula e Bergamácia (PAIVA et al., 2005). Por ser um animal de grande porte e que apre- senta boa capacidade de crescimento e boa produção de leite, a Santa Inês apresenta um importante potencial para produção de meio-sangue em cruzamentos industriais (BARROS et al., 2005).

A Texel é uma raça de origem holandesa, que, em geral, apresenta animais precoces, caracterizando-se pela produção de carcaças de boa qualidade e com baixo teor de gordura. De acordo com LANDIM et al. (2007), é importante o estudo do cruzamento da Texel com a Santa Inês para demonstrar a viabilidade da exploração da complementaridade dessas raças. A Ile de France é considerada raça de duplo propósito, com um equilíbrio zootécnico orientado $60 \%$ para a produção de carne e $40 \%$ para a produção de lã. De acordo com CUNHA et al. (2000), essa raça produz crias pesadas ao nascer, com elevado ganho de peso e elevado peso adulto, o que a torna adequada para o cruzamento industrial.

Existem vários trabalhos mostrando as alternativas para a produção de carne dos cordeiros, dentre elas o confinamento (OTTO et al., 1997; MACEDO et al., 2000; ZUNDT et al., 2002). Porém, são escassos os estudos de viabilidade econômica, os quais são fundamentais para que o criador possa fazer sua opção de maneira objetiva (ZUNDT et al., 2002). O confinamento de cordeiros apresenta uma série de benefícios, como mais baixa mortalidade dos animais devido à menor incidência de verminoses e maior controle da parte nutricional (SIQUEIRA et al., 1993). Além disso, o confinamento de cordeiros agiliza o retorno do capital aplicado, permite a produção de carne de qualidade durante todo o ano e a padronização de carcaças, reduz a idade de abate e disponibiliza a forragem das pastagens para as demais categorias do rebanho (PIRES et al., 2000). No entanto, as maiores desvantagens se encontram nos altos custos de produção, principalmente aqueles relacionados à alimentação, que constitui um fator determinante no aspecto financeiro (OLIVEIRA et al., 2002).

De acordo com BENDAHAN (2006), aspectos como velocidade de acabamento, conversão alimentar, qualidade dos animais disponíveis, preço e qualidade da alimentação e mercado demandador de carne de qualidade devem ser levados em conta na opção pelo confinamento, para que o produtor obtenha ganho econômico na atividade. Assim, teve-se como objetivo do presente estudo avaliar a viabilidade econômica 
da produção de cordeiros cruzados em confinamento, além de determinar qual o peso de abate mais rentável.

\section{MATERIAL E MÉTODOS}

Este experimento foi desenvolvido nos anos de 2007 e 2008 no Centro de Manejo de Ovinos, na Fazenda Água Limpa, da Universidade de Brasília (UnB), nas proximidades da cidade de Brasília (DF). O clima da região é do tipo AW pela classificação de Köppen, com temperatura média anual de $21,1^{\circ} \mathrm{C}$, tendo $16^{\circ} \mathrm{C}$ e $34{ }^{\circ} \mathrm{C}$ como mínima e máxima absolutas, respectivamente. A precipitação anual média é de $1.578,5 \mathrm{~mm}$ e a média anual de umidade relativa do ar é de $68 \%$.

Utilizaram-se 53 ovinos machos e fêmeas, de parto simples e gemelar, oriundos de três grupos genéticos diferentes, sendo 24 animais da raça Santa Inês (SI), 21 oriundos do cruzamento das raças Ile de France x Santa Inês (ILE x SI), e 8 oriundos do cruzamento entre Texel x Santa Inês (TX x SI). As raças Texel e Ile de France foram utilizadas como raça paterna.

Ao nascer, os cordeiros foram identificados individualmente, com acesso livre ao creep-feeding, e permaneceram junto de suas respectivas mães até atingirem o peso de $18 \mathrm{~kg}$, para o desmame. As pesagens dos cordeiros foram realizadas semanalmente.

A dieta era constituída de concentrado - composto por milho em grão $(56,14 \%)$, farelo de soja $(29,57 \%)$, farelo de trigo $(10,29 \%)$ e núcleo mineral vitamínico $(4 \%)$ - e volumoso, sendo feno de coast-cross (Cynodon dactylon (L.) Pers). A dieta, cuja análise bromatológica encontra-se na Tabela 1 , foi fornecida ad libitum.

TABELA 1. Composição bromatológica da dieta experimental

\begin{tabular}{lcc}
\hline \multicolumn{1}{c}{ Componentes } & Concentrado & Volumoso \\
\hline Matéria seca (MS) & 90,93 & 81,93 \\
Fibra em detergente neutro (FDN)* & 32,53 & 83,24 \\
Fibra em detergente ácido (FDA)* $^{*}$ & 43,18 & 8,80 \\
Proteína bruta (PB)* & 18,81 & 2,75 \\
Extrato etéreo (EE)* & 3,23 & 1,73 \\
Matéria mineral (MM)* $^{*}$ & 7,14 & 1,88 \\
\hline
\end{tabular}

* Valores expressos em porcentagem da matéria seca.
A partir da desmama, os animais foram vermifugados e alojados nas áreas de confinamento. A composição bromatológica dos alimentos (concentrado e volumoso) usados no confinamento foi semelhante à dos utilizados até o desmame, pois os ingredientes da dieta se diferenciaram apenas em relação ao núcleo mineral vitamínico. Baseou-se o fornecimento da dieta na ingestão de matéria seca (IMS) estimada, que ficou em torno de $3 \%$ do peso vivo (PV) do animal. O concentrado ( $70 \%$ da IMS total) e o feno ( $30 \%$ da IMS total), foram distribuídos duas vezes ao dia, às 8 e às 16 horas. A pesagem dos animais foi feita semanalmente, assim como a revisão das quantidades de ração e feno que seriam disponibilizadas. $\mathrm{O}$ abate, por casualização ocorreu quando os animais atingiram os pesos de 30 , 35,40 e $45 \mathrm{~kg}$.

Para a análise de viabilidade econômica do experimento, buscou-se comparar os tratamentos avaliados. Tendo-se em vista que os custos fixos nos três tratamentos eram idênticos, teriam que ser considerados, para fins de comparação, apenas os custos variáveis. Assim, a análise econômica foi baseada no cálculo da margem bruta, que consiste na diferença entre a receita bruta e os custos variáveis. De acordo com BARROS et al. (2005), apesar de considerar apenas os custos variáveis, a margem bruta fornece um indicativo de viabilidade econômica de uma atividade, pois se o produtor já tem a infraestrutura montada, os custos fixos já existem, independentemente do uso ou não das instalações. Assim, os custos variáveis eram os que mais poderiam variar de um tratamento para o outro e, por isso, formaram, juntamente com a receita bruta, a base para a análise.

O custo variável foi composto pelos seguintes custos operacionais: alimentação no creep-feeding e no confinamento dos cordeiros, mão de obra durante todo o período, alimentação das matrizes e custo sanitário. Para o levantamento desses gastos, fez-se a cotação dos preços dos produtos no Distrito Federal, no período de abril a junho de 2008, optando-se pelo menor preço encontrado após a cotação em três locais diferentes de venda.

O custo operacional relativo ao aspecto sanitário (denominado apenas custo sanitário) incluiu as despesas com vermífugos, vacinas e outros medicamentos. Foram denominados desta forma os antibióticos, anti-inflamatórios e demais medicamentos que, porventura, 
foram necessários. $\mathrm{O}$ custo estimado destes foi de $\mathrm{R} \$$ 0,50 por cordeiro e por ovelha. $\mathrm{O}$ custo sanitário das ovelhas foi considerado durante o período necessário para a produção de um cordeiro. Os valores estão discriminados na Tabela 2, sendo que o gasto foi considerado igual para todos os animais.

A ingestão diária de alimentos pelos cordeiros no creep-feeding foi estimada em $200 \mathrm{~g}$ de concentrado e $100 \mathrm{~g}$ de volumoso. A estimativa foi realizada com base no consumo total diário observado no grupo em estudo. O custo do concentrado utilizado está demonstrado na Tabela 3 . O custo do feno de coast-cross foi $\mathrm{R} \$ 0,16 / \mathrm{kg}$.

TABELA 2. Custo sanitário anual para criação de ovinos em confinamento no DF

\begin{tabular}{|c|c|c|c|c|}
\hline & Descrição & $\begin{array}{c}\text { Custo da } \\
\text { dose } \\
\text { RS }\end{array}$ & $\begin{array}{c}\text { Cordeiros } \\
\text { custo/ cab } \\
\mathrm{R} \$\end{array}$ & $\begin{array}{c}\text { Ovelhas } \\
\text { custo/ cab } \\
\text { R\$ }\end{array}$ \\
\hline \multirow{3}{*}{$\begin{array}{l}\text { Antipa- } \\
\text { rasitários }\end{array}$} & Albendazole & 0,05 & 0,05 & 0,05 \\
\hline & Fenbendazole & 0,26 & 0,26 & \\
\hline & Coccidiostático & 0,14 & 0,14 & \\
\hline \multicolumn{2}{|c|}{ Polivacina $^{1}$} & 0,72 & 0,72 & 0,72 \\
\hline \multicolumn{2}{|c|}{ Vacina antirrábica } & 0,45 & 0,45 & \\
\hline \multicolumn{2}{|c|}{ Outros medicamentos $^{2}$} & 0,50 & 0,50 & 0,50 \\
\hline \multicolumn{2}{|c|}{ Custo sanitário } & & 2,12 & 1,27 \\
\hline
\end{tabular}

${ }^{1}$ Vacina contra carbúnculo sintomático, gangrena gasosa, botulismo.

${ }^{2}$ Antibióticos, anti-inflamatórios e demais medicamentos.

TABELA 3. Custo do concentrado utilizado no creep-feeding de cordeiros cruzados criados no DF

\begin{tabular}{|c|c|c|c|}
\hline \multirow{2}{*}{ Concentrado } & \multicolumn{3}{|c|}{ Proporção Preço (R\$/ Custo Total } \\
\hline & $(\%)$ & $\mathrm{kg})$ & $(\mathrm{R} \$ / \mathrm{kg})$ \\
\hline Farelo de soja & 29,57 & 0,70 & 0,21 \\
\hline Farelo de trigo & 10,29 & 0,34 & 0,03 \\
\hline Milho em grão & 56,14 & 0,40 & 0,22 \\
\hline Núcleo mineral vitamínico & 4,00 & 1,11 & 0,05 \\
\hline \multicolumn{3}{|c|}{ Custo total por kg do concentrado } & 0,51 \\
\hline
\end{tabular}

O custo do concentrado utilizado no confinamento está demonstrado na Tabela 4. Para a análise do custo da alimentação com os cordeiros confinados, calculou-se a média de peso do animal durante o período que esteve no confinamento. Esta média foi multiplicada por $2,1 \%$, correspondentes à ingestão média diária de concentrado, e por $0,9 \%$, relativo à ingestão média diária de volumoso. Ao final, o custo diário da alimentação foi multiplicado pela quantidade de dias que o cordeiro permaneceu no confinamento até atingir o peso de abate. Estimou-se a ingestão de sal mineral em $8 \mathrm{~g} / \mathrm{animal} /$ dia, o que está de acordo com SILVA et al. (2006). O custo médio do sal mineral utilizado foi $\mathrm{R} \$ 1,50 / \mathrm{kg}$.

TABELA 4. Custo do concentrado utilizado no confinamento de cordeiros cruzados criados no DF

\begin{tabular}{lccc}
\hline Concentrado & $\begin{array}{c}\text { Proporção } \\
(\%)\end{array}$ & Preço $(\mathrm{R} \$ / \mathrm{kg})$ & $\begin{array}{c}\text { Custo Total } \\
(\mathrm{R} \$ / \mathrm{kg})\end{array}$ \\
\hline Farelo de soja & 29,57 & 0,70 & 0,21 \\
Farelo de trigo & 10,29 & 0,34 & 0,03 \\
$\begin{array}{l}\text { Milho em grão } \\
\text { N ú c l e o m i n e r a 1 }\end{array}$ & 56,14 & 0,40 & 0,22 \\
vitamínico & 4,00 & 0,94 & 0,04 \\
Custo total por kg do concentrado & & 0,50 \\
\hline
\end{tabular}

O custo operacional para manutenção de uma ovelha durante o período necessário para que ela tenha um parto foi denominado como custo ovelha. $\mathrm{O}$ cálculo desse custo baseou-se no confinamento da ovelha nos primeiros quinze dias pós-parto e na sua manutenção a pasto no restante do tempo. A duração do período a pasto foi calculada a partir do número de dias que o cordeiro permaneceu no creep-feeding (subtraídos os quinze dias de confinamento pós-parto), adicionados do tempo necessário para uma gestação (150 dias), mais vinte dias entre o desmame e uma nova concepção. $\mathrm{O}$ período a pasto apresentou uma média de 232 dias. A duração de todo o período foi, em média, 247 dias.

Considerou-se que durante todo o tempo (tanto no confinamento quanto a pasto) o fornecimento diário de concentrado seria de $200 \mathrm{~g} / \mathrm{animal} / \mathrm{dia}$. O concentrado seria o mesmo utilizado no confinamento dos cordeiros. O consumo de volumoso estimado foi de 1 $\mathrm{kg} /$ ovelha/dia, baseado em uma ingestão de $2,5 \%$ do PV e em uma média de $40 \mathrm{~kg}$ de PV da ovelha.

Baseou-se o custo da pastagem nos custos de formação, de $\mathrm{R} \$ 1.010,10$, e de manutenção, de $\mathrm{R} \$$ 230,52 por ano, por hectare (SILVA et al., 2006). Foi considerado um período de vida útil da pastagem de dez anos, sendo o custo com a formação dividido por 
esse período, obtendo-se o custo de R $\$ 331,53 / \mathrm{ha} / \mathrm{ano}$. Estimando-se uma taxa de lotação de quinze ovelhas por hectare (SILVA et al., 2006), chegou-se ao custo anual da pastagem de $\mathrm{R} \$ 22,10$ /ovelha.

A ingestão de sal mineral foi estimada em $10 \mathrm{~g} /$ ovelha/dia (SILVA et al., 2006), o que representou uma despesa de R \$ 0,015/dia. O custo sanitário da ovelha (Tabela 2) está incluído no cálculo do custo ovelha.

A ocupação de mão de obra foi estimada em 2 $\mathrm{h} /$ homem/dia para todos os animais do experimento, o que corresponde ao tempo necessário para o fornecimento da alimentação aos animais e limpeza das instalações. O custo operacional com mão de obra foi estimado com base no valor do salário mínimo vigente ( $\$$ \$ 415,00), acrescido de 40\% de encargos sociais. Essa forma de cálculo está de acordo com a que é utilizada por BARROS et al. (2005). O custo total foi dividido pelo número de animais (53) e multiplicado pelo tempo que o animal permaneceu em creep e em confinamento. $\mathrm{O}$ custo operacional da mão de obra foi $\mathrm{R} \$ 0,14 /$ cabeça/dia.

Obteve-se a receita bruta a partir da venda dos cordeiros para o abate. Considerou-se o preço dos animais em R \$ 3,50/kg de PV. Esse valor está de acordo com o praticado durante o ano de 2008 para animais jovens, na região.

Os dados foram analisados com uso de custos individuais por animal no experimento. O programa SAS ${ }^{\circledR}$ foi utilizado para determinar o efeito de grupo genético, peso de abate e sexo, bem como suas interações sobre os gastos calculados. Os procedimentos incluíram Proc GLM (com teste de Tukey a 5\%), PRINCOMP e CORR.

\section{RESULTADOS E DISCUSSÃO}

O custo operacional final do creep-feeding por animal não apresentou diferença significativa entre as raças, o sexo ou o peso de abate (PA). O custo ovelha está incluído no custo final do creep-feeding e também não teve diferença significativa. O custo ovelha foi de $\mathrm{R} \$ 41,59$, em média, e representou $38 \%$ do custo final de produção do cordeiro.

No caso de parto gemelar, o custo ovelha foi de $\mathrm{R} \$ 20,80$ /cordeiro, em média, o que representa apenas $16 \%$ do custo final do cordeiro. Isso pode constituir uma fonte significativa de redução das despesas. No en- tanto, BARROS et al. (2005) observaram que animais de nascimento simples apresentam maior potencial de crescimento do que os de nascimento duplo, o que pode influenciar no custo final dos cordeiros.

O custo operacional do creep-feeding representou $48 \%$ do custo final do cordeiro, sendo em média R \$ 62,92/animal. O custo operacional de mão de obra representou apenas $17 \%$ do custo operacional total do creep-feeding e não apresentou diferença estatística significativa entre os pesos de abate.

O número de dias em confinamento, o custo do concentrado, o custo do volumoso e o custo total da alimentação apresentaram diferença significativa entre os pesos de abate (Tabela 5). Animais com maior peso de abate permanecem maior tempo em confinamento, demandando maior quantidade de alimento. O consumo médio de concentrado no confinamento foi de 486 g/animal/dia, para o grupo abatido com $30 \mathrm{~kg}$ de PV, e $627 \mathrm{~g} /$ animal/dia, para o grupo abatido com $45 \mathrm{~kg}$ de PV. A ingestão de volumoso foi de 208 e 269 g/animal/ dia, respectivamente, para esses grupos.

O sexo também fez diferença nos dias em confinamento. As fêmeas apresentaram uma média de 155 dias de confinamento, e os machos, de 128 dias, o que está de acordo com ROSA et al. (2002) e RIBEIRO et al. (2001). Os autores afirmam que machos inteiros têm velocidade de crescimento maior que a dos castrados e estes maior que a das fêmeas. Esses resultados, no entanto, contradizem os encontrados por CARVALHO et al. (1999) e CARNEIRO et al. (2007). Os primeiros autores, trabalhando com cordeiros (machos e fêmeas) $3 / 4$ Texel 1/4 Ideal, concluíram que quanto ao desempenho, consumo e conversão alimentar, não houve evidência de superioridade de machos sobre fêmeas. CARNEIRO et al. (2007) observaram que o sexo não influenciou $(p>0,05)$ o peso dos animais. Provavelmente, a idade de abate muito reduzida tenha sido um fator limitante para que não houvesse diferenças acentuadas em relação ao desempenho dos animais. Possivelmente, em uma idade mais avançada haveria maior ação da testosterona, proporcionando benefícios para os machos inteiros em relação às fêmeas.

O custo operacional final do confinamento apresentou diferenças significativas de acordo com as raças, os sexos e os pesos de abate. O mesmo ocorreu com o custo operacional da mão de obra. Isso está relacionado com a variação da duração do confinamento, pois o cus- 
to da mão de obra se torna mais expressivo conforme aumenta o período em que o animal está confinado. Os custos finais do confinamento e por cordeiro também apresentaram diferenças significativas conforme a raça, o peso de abate e o sexo.

Os custos operacionais do confinamento, por cordeiro (parto simples e gemelar), por $\mathrm{kg}$ de peso vivo (PV) e por kg de carcaça obtidos estão apresentados na Tabela 7. O custo por cordeiro de parto gemelar (Tabela 6) representa o custo operacional total que o animal teria se fosse oriundo de um parto gemelar. Este apresentou diferença significativa conforme o PA, o sexo e a raça. O custo operacional por $\mathrm{kg}$ de $\mathrm{PV}$ produzido teve maior diferença entre as raças e os sexos. A diferença também foi significativa nas interações raça $x$ PA e PA $x$ sexo. O custo operacional médio encontrado foi de $\mathrm{R} \$ 3,74 / \mathrm{kg}$ de PV.

Para o custo do kg de carcaça, apenas as interações raça $x$ PA e PA $x$ sexo mostraram diferença estatística significativa. Esse fato indica que a alteração no rendimento da carcaça entre as raças e entre os sexos compensou o maior custo do $\mathrm{kg}$ de $\mathrm{PV}$, pois diminuiu as diferenças no custo da carcaça produzida. No custo operacional médio do peso vivo houve diferença significativa entre fêmeas (R\$ $3,92 / \mathrm{kg}$ de PV) e machos (R\$3,57/kg de PV). Já no custo operacional médio da carcaça das fêmeas, de R $\$ 7,52 / \mathrm{kg}$, e dos machos, de $\mathrm{R} \$ 7,11 / \mathrm{kg}$, não foi encontrada diferença significativa.

TABELA 5. Custos com alimentação de cordeiros em confinamento no DF

\begin{tabular}{|c|c|c|c|c|}
\hline & Dias de confinamento & Concentrado $^{1} \mathrm{R} \$$ & Volumoso $^{1} \mathrm{R} \$$ & $\begin{array}{c}\text { Alimentação }^{1} \\
\text { R\$ }\end{array}$ \\
\hline $\mathrm{R}^{2}$ & 0,76 & 0,90 & 0,90 & 0,90 \\
\hline $\mathrm{CV}$ & 16,95 & 4,18 & 4,18 & 4,03 \\
\hline Média & 140,94 & 0,28 & 0,04 & 0,33 \\
\hline Raça & $*$ & $\mathrm{P}<0,10$ & $\mathrm{P}<0,10$ & $\mathrm{P}<0,10$ \\
\hline $\mathrm{PA}$ & $* * *$ & $* * *$ & $* * *$ & $* * *$ \\
\hline Raça $x$ PA & $\mathrm{P}<0,10$ & ns & ns & ns \\
\hline Sexo & $* *$ & ns & ns & ns \\
\hline Raça $x$ sexo & Ns & ns & ns & ns \\
\hline PA $x$ sexo & Ns & ns & ns & ns \\
\hline Raca $x$ PA $x$ & $\mathrm{P}<0,10$ & ns & ns & ns \\
\hline
\end{tabular}

${ }^{*} \mathrm{P}<0,05 ;{ }^{*} \mathrm{P}<0,01 ;{ }^{*} * \mathrm{P}<0,001$. NS: não significativo, usando o teste de Tukey; $\mathrm{R}^{2}$ : coeficiente de determinação; CV: coeficiente de variação; PA: peso de abate.

${ }^{1}$ Custos expressos em valores diários.

TABELA 6. Custos operacionais finais da criação de ovinos em confinamento no DF

\begin{tabular}{|c|c|c|c|c|c|}
\hline & $\begin{array}{c}\text { Confinamento } \\
\text { RS }\end{array}$ & $\begin{array}{l}\text { Cordeiro }^{1} \\
\mathrm{R} \$\end{array}$ & $\begin{array}{c}\text { Cordeiro } \\
\text { (gemelar) }{ }^{2} \mathrm{R} \$\end{array}$ & $\begin{array}{c}\mathrm{Kg} \text { peso vivo } \\
\mathrm{RS}\end{array}$ & $\begin{array}{c}\text { Kg carcaça } \\
\mathrm{R} \$\end{array}$ \\
\hline $\mathrm{R}^{2}$ & 0,83 & 0,77 & 0,79 & 0,63 & 0,57 \\
\hline $\mathrm{CV}$ & 16,16 & 9,55 & 10,73 & 11,49 & 12,80 \\
\hline Média & 66,99 & 129,91 & 109,11 & 3,74 & 7,31 \\
\hline Raça & $*$ & $*$ & $*$ & $* *$ & $\mathrm{P}<0,10$ \\
\hline PA & $* * *$ & $* * *$ & $* * *$ & ns & ns \\
\hline Raça $x$ PA & ns & ns & ns & $*$ & $*$ \\
\hline Sexo & $* *$ & $* *$ & $* *$ & $* *$ & $\mathrm{P}<0,10$ \\
\hline Raça $x$ sexo & ns & ns & ns & $\mathrm{ns}$ & $\mathrm{ns}$ \\
\hline PA $x$ sexo & ns & $\mathrm{P}<0,10$ & $\mathrm{P}<0,10$ & $*$ & $*$ \\
\hline Raça $x$ PA $x$ sexo & $*$ & ns & $\mathrm{P}<0,10$ & ns & $\mathrm{ns}$ \\
\hline
\end{tabular}

${ }^{*} \mathrm{P}<0,05 ; * * \mathrm{P}<0,01 ; * * * \mathrm{P}<0,001$. NS: não significativo, usando o teste de Tukey; $\mathrm{R}^{2}$ : coeficiente de determinação; CV: coeficiente de variação; PA: peso de abate.

${ }^{1}$ Custo final por cordeiro oriundo de parto simples.

${ }^{2} \mathrm{Custo}$ final por cordeiro oriundo de parto gemelar. 
Os custos operacionais da alimentação e da mão de obra no confinamento representaram $69 \%$ e $29 \%$, respectivamente, do custo operacional final. A mão de obra e a alimentação são as principais fontes de custos variáveis, em confinamento.

A grande influência do custo da alimentação (concentrado e forrageiras conservadas) no custo da carcaça produzida em confinamento foi observada por MACEDO (1998). Em estudos desenvolvidos por esse autor, o custo de produção do quilograma da carcaça foi de $\mathrm{R} \$ 2,26$ para os cordeiros em pastagem e de $\mathrm{R} \$$ 2,31 para os cordeiros confinados.

A receita bruta teve uma diferença de grande significância conforme os pesos de abate. Isso é explicado pelo fato de o pagamento ser feito pelo PV, ou seja, animais com maior peso representam maior receita bruta. A diferença entre a receita bruta e o custo operacional total (denominada margem bruta) apresentou diferença significativa de acordo com a raça, o sexo e a interação PA x sexo (Tabela 8).

No caso dos animais oriundos de parto gemelar, a margem bruta foi R\$13,71/animal, em média. Essa margem foi significativamente diferente conforme o sexo e a raça, além da interação PA $x$ sexo. O parto gemelar apenas aumentou a diferença, apresentando comportamento estatístico semelhante ao da margem bruta dos animais oriundos de parto simples (Tabela 7).

TABELA 7. Receita e margem bruta para a criação de ovinos no DF

\begin{tabular}{|c|c|c|c|}
\hline & $\begin{array}{c}\text { Receita } \\
\mathrm{R} \$\end{array}$ & $\begin{array}{c}\text { Margem } \text { bruta }^{1} \\
\text { R\$ }\end{array}$ & 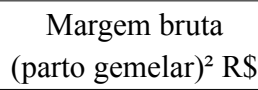 \\
\hline$\overline{\mathrm{R}^{2}}$ & 0,92 & 0,61 & 0,62 \\
\hline $\mathrm{CV}$ & 5,63 & $-208,76$ & 103,21 \\
\hline Média & 122,83 & $-7,08$ & 13,71 \\
\hline Raça & $\mathrm{P}<0,10$ & $* *$ & $* *$ \\
\hline PA & $* * *$ & ns & Ns \\
\hline Raça $x$ PA & ns & $\mathrm{P}<0,10$ & $\mathrm{P}<0,10$ \\
\hline Sexo & ns & $* *$ & $* *$ \\
\hline Raça $x$ sexo & ns & ns & Ns \\
\hline PA $x$ sexo & ns & * & $*$ \\
\hline Raça $x$ PA $x$ sexo & ns & ns & Ns \\
\hline
\end{tabular}

$* \mathrm{P}<0,05 ; * * \mathrm{P}<0,01 ; * * * \mathrm{P}<0,001$. NS: não significativo, usando o teste de Tukey; $\mathrm{R}^{2}$ : coeficiente de determinação; CV: coeficiente de variação; PA: peso de abate.

${ }^{1}$ Margem bruta calculada em valores individuais para cada animal.

${ }^{2}$ Margem bruta para animais oriundos de partos gemelares.

TABELA 8. Custos operacionais com diferença significativa entre os grupos raciais de ovinos criados em confinamento no DF

\begin{tabular}{lccccc}
\hline Raça & Concentrado $^{1}$ & Volumoso $^{1}$ & Alimentação $^{1}$ & kg PV & Kg carcaça \\
\hline SI & $0,27^{\mathrm{b}}$ & $0,037^{\mathrm{b}}$ & $0,32^{\mathrm{b}}$ & $4,01^{\mathrm{a}}$ & $7,66^{\mathrm{a}}$ \\
ILXSI & $0,28^{\mathrm{b}}$ & $0,038^{\mathrm{b}}$ & $0,33^{\mathrm{b}}$ & $3,58^{\mathrm{b}}$ & $7,13^{\mathrm{ab}}$ \\
TXSI & $0,30^{\mathrm{a}}$ & $0,04^{\mathrm{a}}$ & $0,35^{\mathrm{a}}$ & $3,38^{\mathrm{b}}$ & $6,72^{\mathrm{b}}$ \\
\hline
\end{tabular}

Letras distintas na mesma coluna significam diferença significativa entre as médias usando o teste de Tukey $(\mathrm{P}<0.05)$.

SI: Santa Inês; ILXSI: cruzamento entre as raças Ile de France e Santa Inês; TXSI: cruzamento entre as raças Texel e Santa Inês.

Todos os valores estão expressos em reais ( $\mathrm{R} \$)$.

${ }^{1}$ Custos expressos em valores diários.

A raça e o sexo influenciaram significativamente no custo operacional do kg de PV e de carcaça produ- zidos. Os valores foram de $\mathrm{R} \$ 4,01 / \mathrm{kg}$ de $\mathrm{PV}$ para o cruzamento com Santa Inês e de R \$3,38/kg de PV para 
o cruzamento com Texel (Tabela 8). Esses resultados demonstram a capacidade de redução nos custos de produção por meio do cruzamento de Santa Inês com Ile de France e Texel.

Os animais abatidos com $45 \mathrm{~kg}$ de PV apresentaram custo operacional de $\mathrm{R} \$ 3,51 / \mathrm{kg}$ de $\mathrm{PV}$ produzido, significativamente menor que os demais grupos (Tabela 9). $\mathrm{O}$ grupo abatido com $30 \mathrm{~kg}$ de PV teve custo de R $\$ 3,89 / \mathrm{kg}$ de PV. O maior peso de abate está relacionado com aumento da receita bruta e menor participação dos custos do creep e da ovelha no custo final do cordeiro.

CARDOSO (2008), trabalhando com os mesmos grupos genéticos deste estudo, observou maior qualidade de carcaça para os animais abatidos com $35 \mathrm{Kg}$ de PV. Isso demonstra que para o criador fornecer carne de boa qualidade para o mercado é fundamental o estabelecimento de sistemas de pagamento pela carne com premiação por qualidade, fazendo que o peso de melhor qualidade de carcaça se torne o peso de maior rentabilidade econômica.

TABELA 9. Custos operacionais que apresentaram diferença significativa entre os pesos de abate para cordeiros criados em confinamento no DF

\begin{tabular}{ccccccc}
\hline Peso de Abate & Alimentação $^{1}$ & $\mathrm{MO}^{2}$ & Confinamento & Cordeiro & Kg PV & Kg carcaça \\
\hline $30 \mathrm{~kg}$ & $0,29^{\mathrm{d}}$ & $13,58^{\mathrm{c}}$ & $42,77^{\mathrm{c}}$ & $108,90^{\mathrm{c}}$ & $3,89^{\mathrm{a}}$ & $8,01^{\mathrm{a}}$ \\
$35 \mathrm{~kg}$ & $0,31^{\mathrm{c}}$ & $17,37^{\mathrm{b}}$ & $57,29^{\mathrm{b}}$ & $121,34^{\mathrm{b}}$ & $3,82^{\mathrm{ab}}$ & $7,28^{\mathrm{ab}}$ \\
$40 \mathrm{~kg}$ & $0,34^{\mathrm{b}}$ & $22,21^{\mathrm{a}}$ & $77,04^{\mathrm{a}}$ & $138,59^{\mathrm{a}}$ & $3,81^{\mathrm{ab}}$ & $7,27^{\mathrm{ab}}$ \\
$45 \mathrm{~kg}$ & $0,37^{\mathrm{a}}$ & $22,90^{\mathrm{a}}$ & $85,22^{\mathrm{a}}$ & $145,89^{\mathrm{a}}$ & $3,51^{\mathrm{b}}$ & $6,88^{\mathrm{b}}$ \\
\hline
\end{tabular}

Letras distintas na mesma coluna significam diferença significativa entre as médias usando o teste de Tukey $(\mathrm{P}<0,05)$.

Todos os valores estão expressos em reais (R\$)

${ }^{1}$ Custos expressos em valores diários.

${ }^{2}$ Custo da mão de obra durante todo o período do confinamento.

BARROS et al. (2005) avaliaram a eficiência bioeconômica de cordeiros F1 Dorper x Santa Inês para produção de carne. Obtiveram um custo operacional de $\mathrm{R} \$ 2,24, \mathrm{R} \$ 2,20$ e $\mathrm{R} \$ 2,14 / \mathrm{kg}$ de PV (respectivamente, para os níveis de concentrado na dieta de 1,5\%,2,5\% e 3,5 \% do PV). Então, apesar de se ter um aumento significativo nos custos totais, com alimentação em níveis mais elevados de uso de concentrado, a resposta produtiva (aumento da produção) compensou o aumento de custos, de forma a proporcionar melhor resultado econômico, ao se optar por usar quantidade mais elevada de concentrado. No presente estudo foi utilizada a quantidade de $2,1 \%$ do PV de concentrado na dieta, o que pode ter colaborado para o baixo retorno econômico observado.

ZUNDT et al. (2002), testando níveis diferentes de proteína na dieta $(12 \%, 16 \%, 20 \%$ e $24 \%)$, chegaram a um custo médio da carcaça produzida de $\mathrm{R} \$ 2,53 / \mathrm{kg}$. Considerando o preço médio de comercialização em $\mathrm{R} \$ 4,50$, verificou-se retorno econômico para machos e fêmeas em qualquer um dos níveis de proteína na dieta utilizados na terminação dos cordeiros; entretanto, o maior retorno foi conseguido com a dieta contendo $12 \% \mathrm{~PB}$, que deve ser o nível recomendado. Este estudo utilizou uma dieta de aproximadamente $14 \% \mathrm{~PB}$, que, portanto, está bem próximo do nível recomendado. O preço de comercialização utilizado por ZUNDT et al. (2002) é maior que o utilizado neste estudo, o que pode ter contribuído para o retorno econômico encontrado.

A Figura 1 mostra os primeiros dois autovetores que explicaram $83,88 \%$ do total de variação entre as características. O autovetor 1 , que explica $50,23 \%$ da variação observada entre as características, revela que um animal abatido mais pesado teve custo operacional por $\mathrm{kg}$ de peso vivo e de carcaça menor, assim como um custo ovelha menor, confirmando o que foi observado anteriormente. O autovetor 2 demonstra que os grupos com custos operacionais individuais e dias em confinamento maiores estiveram relacionados com margem bruta menor, o que deve ser evitado. 


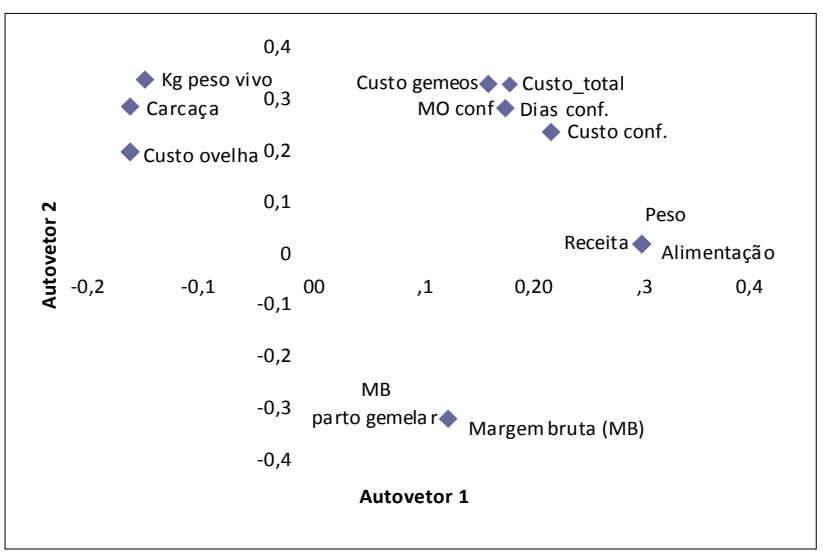

FIGURA 1. Autovetores dos parâmetros avaliados para criação de cordeiros em confinamento no DF

\section{CONCLUSÃO}

O cruzamento foi capaz de diminuir significativamente o custo do $\mathrm{kg}$ de $\mathrm{PV}$ e de carcaça produzido. $\mathrm{O}$ peso de abate mais rentável foi $45 \mathrm{~kg}$ de $\mathrm{PV}$. Com uma receita de $\mathrm{R} \$ 3,50 / \mathrm{kg}$ de $\mathrm{PV}$, a ovinocultura não é lucrativa no DF, já que o custo operacional médio foi de $\mathrm{R} \$ 3,74 / \mathrm{kg}$ de PV. O uso de práticas de manejo para atingir maior índice de partos duplos pode aumentar a margem de lucro da atividade. O pagamento pelo peso de carcaça e por qualidade da carne e a busca por melhores índices de produtividade e melhor conversão alimentar, obtidos por programas de melhoramento genético, são urgentes para a sustentabilidade da atividade.

\section{AGRADECIMENTO}

Ao CNPq, FINATEC e FAPDF, pelos recursos financeiros e bolsas.

\section{REFERÊNCIAS}

ALMEIDA JR., G. A.; COSTA, C.; MONTEIRO, A. L. G.; GARCIA, C. A. et al. Qualidade de carne de cordeiros criados em creep feeding com silagem de grãos úmidos de milho. Revista Brasileira de Zootecnia, v. 33, n. 4, p. 1.039-1.047, 2004.

BARROS, N. N.; VASCONCELOS, V. R.; WANDER, A. E.; ARAÚJO, M. R. A. Eficiência bioeconômica de cordeiros F1 Dorper x Santa Inês para produção de carne. Pesquisa Agropecuária Brasileira, v. 40, p. 825-831, 2005.
BENDAHAN, A. B. Confinamento de cordeiros: uma alternativa na ovinocultura. Disponível em: <http://www.agroline.com.br/ artigos/artigo.php?id=304>. Acesso em: 31 jul. 2006.

CARDOSO, M. T. M. Abate sequencial de ovinos para determinação de peso de abate. 2008. 106 f. Dissertação (Mestrado em Ciências Animais) - Universidade de Brasília, Faculdade de Agronomia e Medicina Veterinária. Brasília, 2008. Disponível em: http://repositorio.bce.unb.br/bitstream/10482/3986/1/2008_ MaximilianoTadeuMCardoso.pdf. Acesso em: 27 out. 2010.

CARNEIRO, P. L. S.; MALHADO, C. H. M.; JÚNIOR, A. A. O. S.; SILVA, A. G. S.; SANTOS, F. N.; SANTOS, P. F.; PAIVA, S. R. Desenvolvimento ponderal e diversidade fenotípica entre cruzamentos de ovinos Dorper com raças locais. Pesquisa Agropecuária Brasileira, v. 42, n. 7, p. 991-998, jul. 2007.

CARVALHO, S.; PIRES, C. C.; PERES, J. R. R.; ZEPPENFELD, C.; WEISS, A. Desempenho de cordeiros machos inteiros, machos castrados e fêmeas, alimentados em confinamento. Ciência Rural, v. 29, n. 1, p. 129-133, 1999.

CUNHA, E. A; SANTOS, L. E.; BUENO, M. S; RODA, D. S.; LEINZ, F. F; RODRIGUES, C. F. C. Utilização de carneiros de raças de corte para obtenção de cordeiros precoces para abate em plantéis produtores de lã. Revista Brasileira de Zootecnia, v. 29, n. 1, p. 243-252, 2000.

INSTITUTO FNP. ANUALPEC: anuário da pecuária brasileira. 1. ed. São Paulo, 2008. 332 p.

LANDIM, A. V.; MARIANTE, A. S.; McManus, C. M.; GUGEL, R.; PAIVA, S. R. Características quantitativas da carcaça, medidas morfométricas e suas correlações em diferentes genótipos de ovinos. Ciência Animal Brasileira, v. 8, p. 665-676, 2007.

MACEDO, F. A. F.; SIQUEIRA, E. R.; MARTINS, E. N.; MACEDO, R. M. G. Qualidade de carcaças de cordeiros Corriedale, Bergamácia x Corriedale e Hampshire Down $\mathrm{x}$ Corriedale, terminados em pastagem e confinamento. Revista Brasileira de Zootecnia, v. 29, n. 5, p. 1.520-1.527, 2000.

MACEDO, F. A. F.; SIQUEIRA, E. R. D.; MARTINS, E. N. Análise econômica da produção de carne de cordeiros sob dois sistemas de terminação: pastagem e confinamento. Ciência Rural, v. 30, n. 4 , p. $677-680.2000$.

OLIVEIRA, M. V. M.; PÉREZ, J. R. O.; ALVES, E. L.; MARTINS; A. R. V.; LANA; R. P. Rendimento de carcaça, mensurações e pesos dos cortes comerciais de cordeiros Santa Inês e Bergamácia alimentados com dejetos de suínos em confinamento. Revista Brasileira de Zootecnia, v. 31, n. 3, p. 1.451-1.458, 2002.

OTTO, C.; SÁ, J. L.; WOEHL, A. H.; CASTRO, J. A.; REIFUR, L.; VALENTINI, V. M. Estudo econômico da terminação de 
cordeiros a pasto e em confinamento. Revista do Setor de Ciências Agrárias, v. 16, n. 1-2, p. 223-227, 1997.

PAIVA, S. R.; SILVÉRIO, V. C.; EGITO, A. A.; McMANUS, C. M.; FARIA, D. A.; MARIANTE, A. S.; CASTRO, S. T. R.; ALBUQUERQUE, M. S. M.; DERGAM, J. A. Genetic variability of the main Brazilian hair sheep breeds using RAPD-PCR markers and conservation implications. Pesquisa Agropecuária Brasileira, v. 40, n. 9 , p. $887-893,2005$.

PIRES, C. C.; SILVA, L. F.; SCHLICK, F. E.; GUERRA, D. P.; BISCAINO, G.; CARNEIRO, R. M. Cria e terminação de cordeiros confinados. Ciência Rural, v. 30, n. 5, p. 875-880, 2000.

RIBEIRO, E. L. A.; ROCHA, M. A.; MIZUBUTI, I. Y.; SILVA, L. D. F.; RIBEIRO, H. J. S. S.; MORI, R. M. Carcaça de borregos Ile de France inteiros ou castrados e Hampshire Down castrados abatidos aos doze meses de idade. Ciência Rural, v. 31, n. 3, p. 479-482, 2001.

RIBEIRO, J. G. B. L.; MEDEIROS, J. X. Arranjos organizacionais na cadeia produtiva da carne ovina: um estudo de caso no Distrito Federal. Cadernos do CEAM, v. 6, p. 107-162, 2006.
ROSA, G. T.; PIRES, C. C.; SILVA, J. H. S.; MULLER, L. Crescimento de osso, músculo e gordura dos cortes da carcaça de cordeiros e cordeiras em diferentes métodos de alimentação.

Revista Brasileira de Zootecnia, v. 31, n. 6, p. 2.283-2.289, 2002.

SILVA, A. V. R.; SANTO, E. E.; PINTO, B. F.; MARTINS, R. F. S.; LOUVANDINI, H.; ROHR, S. A.; REZENDE, M. J. M.; MURATA, L. S.; QUEIROZ, É. A. P.; PAIVA, S. R.; GARCIA, J. A. S.; McMANUS, C. M. Pesos econômicos para características de produção em ovinos no DF. Cadernos do CEAM (UnB), v. 25, p. $61-82,2006$.

SIQUEIRA, E. R.; AMARANTE, A. F. T.; FERNANDES, S. Estudo comparativo da recria de cordeiros em confinamento e pastagem. Revista Veterinária e Zootecnia, v. 5, p. 17-28, 1993.

ZUNDT, M.; MACEDO, F. A. F.; MARTINS, E. N.; MEXIA, A. A.; YAMAMOTO, S. M. Desempenho de cordeiros alimentados com diferentes níveis protéicos. Revista Brasileira de Zootecnia, v. 31, n. 3, p. 1.307-1.314, 2002. 